\title{
CONTRIBUIÇÕES DO ENFERMEIRO NA PESQUISA BÁSICA: MODELO DE FIXAÇÃO DE CURATIVO EM FERIDAS CUTÂNEAS EXCISIONAIS DE CAMUNDONGOS
}

\author{
Gilmara Lopes Amorim¹ (D), Mariana Raquel Soares Guillen (D), Puebla Cassini Vieira² (D), \\ Lucíola da Silva Barcelos ${ }^{3}$ (D), Eline Lima Borges ${ }^{1, *} \mathbb{C}$
}

\section{RESUMO}

Objetivo: validar método de fixação de curativos em feridas cutâneas excisionais de camundongos. Método: estudo préclínico. Amostra composta por animais da linhagem C57BL/6, que tiveram duas feridas excisionais confeccionadas na região dorsal. Foram avaliados diferentes métodos e produtos, amplamente aceitos na prática clínica, para fixação de curativos no modelo animal. Os desfechos avaliados foram tempo de permanência do curativo e ocorrência de eventos adversos. Resultados: atadura de crepom, fita microporosa e bandagem autoaderente apresentaram menor tempo de permanência quando comparadas ao filme de poliuretano. Esse, por sua vez, variou o tempo quando comparadas diferentes marcas ( $E, F, G$ e H) e número de voltas ao redor do corpo do animal. Com 1 volta, o tempo variou de $<24$ a 36 horas. Com 2 voltas, as marcas E e G permaneceram 48 e 96 horas, respectivamente, e F e H tempo < 24 horas. Filme da marca G, cortado no tamanho $3 \mathrm{~cm} \times 15 \mathrm{~cm}$, dando 2 voltas no corpo do camundongo, manteve o curativo por 96 horas. A pele permaneceu íntegra, sem evento adverso. Conclusão: foi criado modelo de fixação de curativos para feridas em camundongos com produto disponível no Brasil e compatível com a estrutura copórea do animal.

DESCRITORES: Cicatrização. Bandagens. Pesquisa básica. Estomaterapia.

\section{CONTRIBUTIONS OF NURSES IN BASIC RESEARCH: DRESSING FIXATION MODEL FOR EXCISIONAL CUTANEOUS WOUNDS OF MICE}

\begin{abstract}
Objective: validate method of fixation of dressings on excisional cutaneous wounds of mice. Method: preclinical study. Sample made up of animals of the C57BL/6 strain, which had two excision wounds made in the dorsal region. Different methods and products, widely accepted in clinical practice, for fixing dressings in the animal model were evaluated. The evaluated outcomes were the length of stay of the dressing and the occurrence of adverse events. Results: crepe bandage, microporous tape and self-adhesive bandage had a shorter residence time when compared to polyurethane film. This, in turn, varied the time when comparing different marks (E, F, G and H) and number of turns around the animal's body. With 1 lap, the time varied from <24 to 36 hours. With 2 laps, the marks $E$ and $G$ remained 48 and 96 hours, respectively, and $\mathrm{F}$ and $\mathrm{H}$ time $<24$ hours. G-brand film, cut to size $3 \mathrm{~cm} \times 15 \mathrm{~cm}$, giving the mouse body 2 turns, kept the dressing for 96 hours. The skin remained intact, with no adverse event. Conclusion: a dressing fixation model for wounds in mice was created with a product available in Brazil and compatible with the animal's body structure.
\end{abstract}

DESCRIPTORS: Healing. Bandages. Basic research. Stomatherapy.

1. Universidade Federal de Minas Gerais - Escola de Enfermagem - Departamento Enfermagem Básica - Belo Horizonte (MG), Brasil.

2. Universidade do Estado de Minas Gerais - Departamento de Ciências Biológicas - Belo Horizonte (MG), Brasil.

3. Universidade Federal de Minas Gerais - Instituto de Ciências Biológicas - Departamento de Fisiologia e Biofísica - Belo Horizonte (MG), Brasil.

*Autora correspondente: elineufmg@gmail.com

Editor de Seção: Manuela de Mendonça F Coelho

Recebido: Abr. 2021, 01 | Aceito: Abr. 2021, 28

Como citar: Amorim GL; Guillen MRS; Vieira PC; Barcelos LS; Borges EL. Contribuições do enfermeiro na pesquisa básica: modelo de fixação de curativo em feridas cutâneas excisionais de camundongos. ESTIMA, Braz. J. Enterostomal Ther., 2021, 19: e1221. https://doi.org/10.30886/estima.v19.1038_PT 


\title{
CONTRIBUCIONES DEL ENFERMERO EN LA INVESTIGACIÓN BÁSICA: MODELO DE FIJACIÓN DE APÓSITO EN HERIDAS CUTÁNEAS EXCISIONALES DE RATONES
}

\begin{abstract}
RESUMEN
Objetivo: validar método de fijación de apósitos en heridas cutáneas excisionales de ratones. Método: estudio preclínico. Muestra compuesta por animales del linaje C57BL/6 que tuvieron dos heridas excisionales confeccionadas en la región dorsal. Se evaluaron distintos métodos y productos, ampliamente aceptados en la práctica clínica, para fijación de apósitos en el modelo animal. Los resultados evaluados fueron tiempo de permanencia del apósito y ocurrencia de eventos adversos. Resultados: La venda de crepé, la cinta microporosa y el vendaje autoadherente presentaron menor tiempo de permanencia cuando comparados con la película de poliuretano. Esta, a su vez, varió en el tiempo cuando comparadas distintas marcas ( $E, F, G$ y H) y número de vueltas alrededor del cuerpo del animal. Con una vuelta completa, el tiempo varió de menos de 24 a 36 horas. Con dos vueltas, las marcas E y $\mathrm{G}$ permanecieron 48 y 96 horas, respectivamente, y F y H, tiempo igual e inferior a 24 horas. La piel permaneció íntegra, sin evento adverso. Conclusión: se creó un modelo de fijación de apósitos en ratones con un producto disponible en Brasil y compatible con la estructura del cuerpo del animal.
\end{abstract}

DESCRIPTORES: Cicatrización de heridas. Vendages. Investigación básica. Estomaterapia.

\section{INTRODUÇÃO}

Pesquisas básicas podem contribuir para solução de problemas inerentes ao cuidado de enfermagem ${ }^{1}$ quando os resultados da pesquisa permitem sua translação para a prática clínica ${ }^{2}$. O desenvolvimento de pesquisas de modelo experimental por enfermeiros torna-se relevante, pois é possível materializar a realidade e amparar o efeito das intervenções de enfermagem. Destaca-se que o modelo animal permite a avaliação de fenômenos biológicos, podendo ser comparados aos humanos ${ }^{3}$, com ênfase nas pesquisas translacionais.

A experimentação animal permite a compreensão de lacunas de conhecimento relacionado aos processos fisiológicos e patológicos, que podem impactar na prática clínica da enfermagem. Observa-se variabilidade de estudos experimentais que abordam a cicatrização de feridas cutâneas, mas, contraditoriamente, esses estudos são conduzidos por outras categorias profissionais ${ }^{4,5}$. Tal questão pode limitar a concretização das intervenções de enfermagem no tratamento de feridas no âmbito de pesquisas in vivo.

$\mathrm{Na}$ enfermagem ainda se mantém o debate sobre a relevância do uso de animais na pesquisa sobre temáticas dessa área de conhecimento ${ }^{3}$. Contudo alguns estudos começaram a ser produzidos na área, especialmente aqueles visando a integração da ciência básica a conteúdos do reparo tecidual das feridas ${ }^{6,7}$. Acredita-se que o uso das tecnologias disponíveis para o tratamento das feridas cutâneas pode ser aperfeiçoado pela Enfermagem por meio do desenvolvimento de pesquisas experimentais e clínicas ${ }^{8}$. Dessa forma, serão explicados os efeitos desses produtos nas diferentes fases do processo de cicatrização de feridas cutâneas. Nesse contexto, persistem dúvidas sobre a adequada fixação do curativo à pele animal.

O termo fixação de curativo, neste estudo, representa o ato de aplicar um produto para manter a cobertura primária sobre a ferida. Entende-se que a fixação de um curativo deve ser capaz de garantir a manutenção da cobertura sobre o leito da ferida por determinado período de tempo, preservando e protegendo a ferida contra possíveis traumatismos. Portanto, para realizar estudos sobre tratamento de feridas em animais, em especial camundongos cuja natureza é a inquietude e capacidade de retirar tudo que lhe é aplicado no dorso, o primeiro passo é estabelecer um modelo de fixação de curativo condizente com a prática clínica da enfermagem. Assim, o objetivo deste estudo é validar um método de fixação de curativo em feridas cutâneas excisionais de camundongos. 


\section{MÉTODOS}

Trata-se de ensaio pré-clínico com camundongos machos, isogênicos, da linhagem C57BL/6, com idade entre 7 e 8 semanas e peso corporal $\geq 17$ gramas, para avaliação dos desfechos tempo de permanência do curativo e ocorrência de eventos adversos.

Os produtos utilizados para fixação do curativo foram: atadura de crepom fixada com esparadrapo (técnica A) e suturada com linha de algodão (técnica B); bandagem autoaderente fixada sob pressão, conforme recomendação do fabricante (técnica A) e suturada com linha de algodão (técnica B); fita microporosa da marca $3 \mathrm{M}^{\circledR}(\mathrm{C})$ e da $\mathrm{Cremer}^{\circledR}(\mathrm{D})$; filme de poliuretano

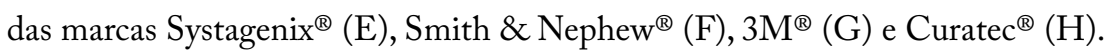

Os diferentes tipos de fixação testados foram repetidos ao menos cinco vezes até serem considerados inapropriados ou apropriados. A seguir, foram utilizados dois animais para o teste da atadura de crepom, dois para fita microporosa, dois para bandagem autoaderente e quatro animais para filme de poliuretano. Os animais foram submetidos à anestesia a cada troca de curativo.

Atadura de crepom, fita microporosa, bandagem autoaderente e filme de poliuretano foram cortados em tiras com, aproximadamente, $3 \mathrm{~cm}$ de comprimento (posição vertical), de forma a envolver toda região dorsal e abdominal do camundongo. A largura (posição horizontal) foi padronizada em $15 \mathrm{~cm}$ para todos os produtos testados, de modo a permitir duas voltas do produto ao redor do corpo do animal. Para o filme de poliuretano também foram utilizadas fitas com largura de $8 \mathrm{~cm}$ no teste, com única volta do filme ao redor do corpo do camundongo.

O estudo também procedeu a avaliação do tamanho da cobertura a ser aplicada na ferida excisional confeccionada com punch cirúrgico de $5 \mathrm{~mm}$. A avaliação contemplou aplicação da cobertura em placa de $1 \mathrm{~cm}^{2}$ (uma para cada ferida) e em formato retangular única, com as seguintes dimensões: $1 \mathrm{~cm}$ de comprimento por $2 \mathrm{~cm}$ de largura, para cobrir toda área das 2 feridas e assegurar pequena margem de sobreposição da pele ao redor delas.

A coleta de dados ocorreu no primeiro semestre de 2019. O estudo envolveu amostra de dez animais, que passaram por cinco dias de ambientação e adaptação antes da realização da ferida excisional e aplicação do curativo. Os animais foram anestesiados com xilazina $2 \%$ na dose de $10 \mathrm{mg} / \mathrm{kg}$ e cetamina $10 \%$ com dose de $100 \mathrm{mg} / \mathrm{kg}$ (fabricante Syntec), preparadas em solução salina $0,9 \%$ estéril e administradas por via intraperitoneal. $\mathrm{Na}$ sequência, esses animais foram submetidos à tricotomia e assepsia da região dorsal. A tricotomia foi realizada com mini-tricotomizador da marca Wall ${ }^{\circledR}$, modelo portátil. A assepsia da pele foi realizada com solução alcoólica a $70 \%$.

Em cada animal foram realizadas duas feridas cutâneas excisionais na região média do dorso com auxílio de um punch cirúrgico dermatológico de $5 \mathrm{~mm}$ de diâmetro. Foi retirada toda extensão do tecido cutâneo, incluindo epiderme, derme, hipoderme e panículo carnoso. As feridas foram confeccionadas com distância mínima de, aproximadamente, $0,5 \mathrm{~cm}$ e máxima de $1,0 \mathrm{~cm}$ entre elas 9 .

A seguir, foi aplicada cobertura sobre a ferida e fixado o curativo a ser avaliado. A aplicação seguiu o modelo de fixação de curativo ${ }^{10}$. A fixação foi aplicada ao redor do corpo do camundongo, de modo a fazer uma ou duas voltas completas ao redor do animal.

A integridade e manutenção da fixação empregada foram avaliadas a cada duas horas nas primeiras seis horas após o término do efeito anestésico, e a cada três horas nas seis horas subsequentes. Após 12 horas do início do experimento, as avaliações foram realizadas a cada 6 horas até o curativo soltar de forma parcial ou completa. Ao término do experimento, inspecionou-se a região ao redor da ferida para avaliação da integridade da pele e identificação de eventos adversos.

Durante o estudo, os animais foram mantidos em sala exclusiva para alojamento desses animais, sob condições controladas de temperatura $\left(24^{\circ} \mathrm{C}\right)$, luminosidade (ciclo claro/escuro 12 horas), em gaiolas individuais (caixa de polipropileno com dimensão aproximada de $25 \mathrm{~cm}^{3}$ ), com distância de $5 \mathrm{~cm}$ (horizontal) e $60 \mathrm{~cm}$ (vertical) entre elas. Os animais tiveram livre acesso à ração e água, e a limpeza das gaiolas foi realizada duas vezes por semana para evitar acúmulo de amônia no ambiente.

Ao término dos experimentos, todos os animais foram eutanasiados com sobredose de anestésico xilazina $2 \%$ na dose de $30 \mathrm{mg} / \mathrm{kg}$ e cetamina $10 \%$ na dose de $300 \mathrm{mg} / \mathrm{kg}$, ambas preparadas em solução salina a $0,9 \%$ estéril, administradas via intraperitoneal, seguida por deslocamento cervical, conforme guia brasileiro de boas práticas para eutanásia de animais, 
Resolução no 714, do Conselho Federal de Medicina Veterinária e Resolução Normativa no 37 do Conselho Nacional de Controle de Experimentação Animal (CONCEA).

O estudo foi aprovado pela Comissão de Ética no Uso de Animais da Universidade Federal de Minas Gerais, sob Protocolo de número 393/2015 e respeitou os princípios éticos de acordo com a legislação vigente para experimentação animal.

\section{RESULTADOS}

O tempo de fixação do curativo variou de 1 a 96 horas, conforme tipo e marca do produto (Tabela 1).

Tabela 1. Fixação de curativo no modelo animal com diversos produtos. Belo Horizonte (MG) - 2019.

\begin{tabular}{lc}
\hline Produto utilizado para fixação & $\begin{array}{c}\text { Permanência do curativo } \\
\text { (horas após término do efeito anestésico) }\end{array}$ \\
\hline Atadura de crepom & 1 hora e 30 minutos \\
\hline$\cdot$ técnica A - fixada com esparadrapo & 1 hora e 30 minutos \\
\hline$\cdot$ técnica B - fixada com sutura & $<5$ horas \\
\hline Bandagem autoaderente & $<5$ horas \\
\hline$\cdot$ técnica A - pressão tátil & 1 a 2 horas \\
\hline$\cdot$ técnica B - sutura & 1 a 2 horas \\
\hline Fita microporosa & \\
\hline$\cdot C(3 M)$ & 48 horas \\
\hline$\cdot D(C r e m e r)$ & 24 horas \\
\hline Filme de poliuretano transparente & 96 horas \\
\hline$\cdot E($ Systagenix $)$ & $\leq 24$ horas \\
\hline$\cdot F($ Smith \& Nephew) & \\
\hline$\cdot G(3 M)$ & (Curatec)
\end{tabular}

A aplicação da atadura de crepom, da bandagem autoaderente e da fita microporosa foi ilustrada na Fig. 1.
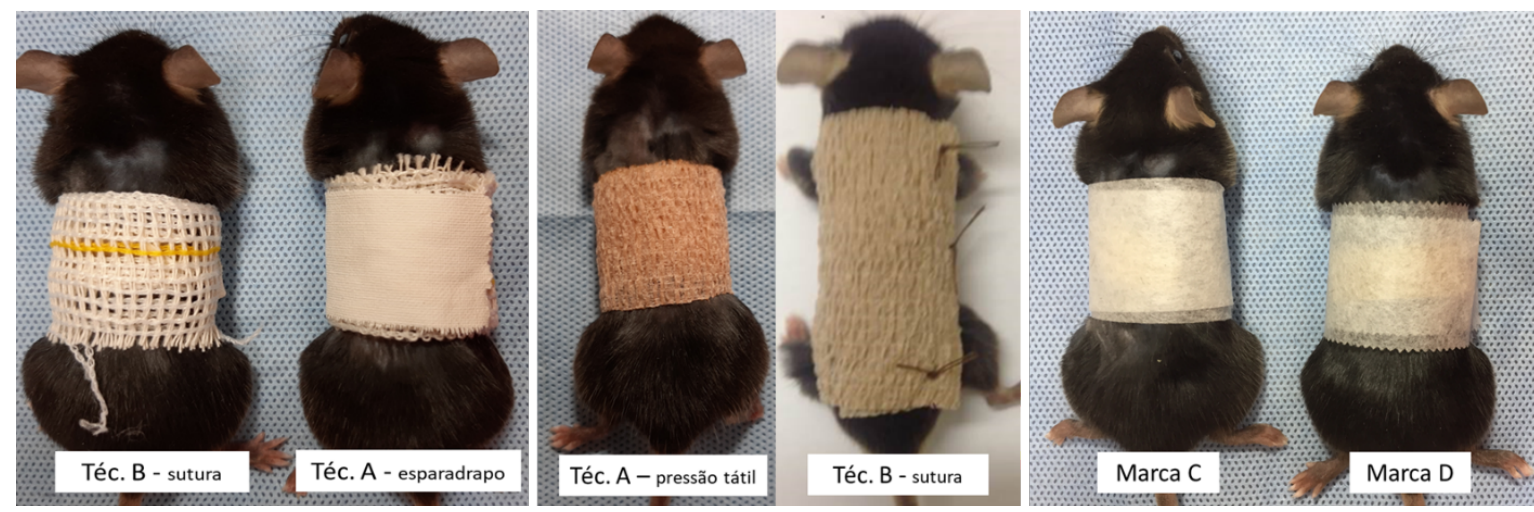

Figura 1. Técnicas de fixação empregadas com atadura de crepom, bandagem autoaderente e fita microporosa. Belo Horizonte (MG) - 2019.

A atadura de crepom foi enrolada ao corpo do animal e a ponta fixada com esparadrapo para simular a realidade da prática clínica (técnica A) e com pontos de sutura (técnica B). Em ambas as formas o tempo de permanência do curativo sobre a ferida não ultrapassou 1 hora e 30 minutos. 
A bandagem autoaderente foi aplicada de duas formas distintas, uma por meio de pressão tátil (técnica A). Porém, não foi possível aplicar pressão adequada para aderência da bandagem devido à estrutura corpórea do camundongo, que não resiste à pressão tátil necessária para autoaderência dessa bandagem. Da outra forma, a bandagem foi aplicada ao redor do corpo do animal e suturada com linha de algodão nas porções proximal e distal (técnica B). Contudo, observou-se que o animal conseguia se esgueirar e sair de dentro da estrutura tubular formada pela bandagem. Nas cinco tentativas realizadas nessa modalidade, o tempo de permanência do curativo no leito da ferida não atingiu cinco horas.

$\mathrm{Na}$ fixação do curativo com fita microporosa marcas $\mathrm{C}\left(3 \mathrm{M}^{\circledR}\right)$ e $\mathrm{D}\left(\right.$ Cremer $\left.^{\circledR}\right)$, o tempo de permanência foi, no máximo, de duas horas para as duas marcas avaliadas. Os animais conseguiram roer a fita nas regiões laterais e, com isso, expor a cobertura primária e as feridas.

O uso do filme de poliuretano como cobertura secundária foi ilustrado na Fig. 2 e a sequência de aplicação dele foi demonstrada na Fig. 3, como cobertura primária (a a d) e cobertura secundária (a’ a d’), respectivamente.
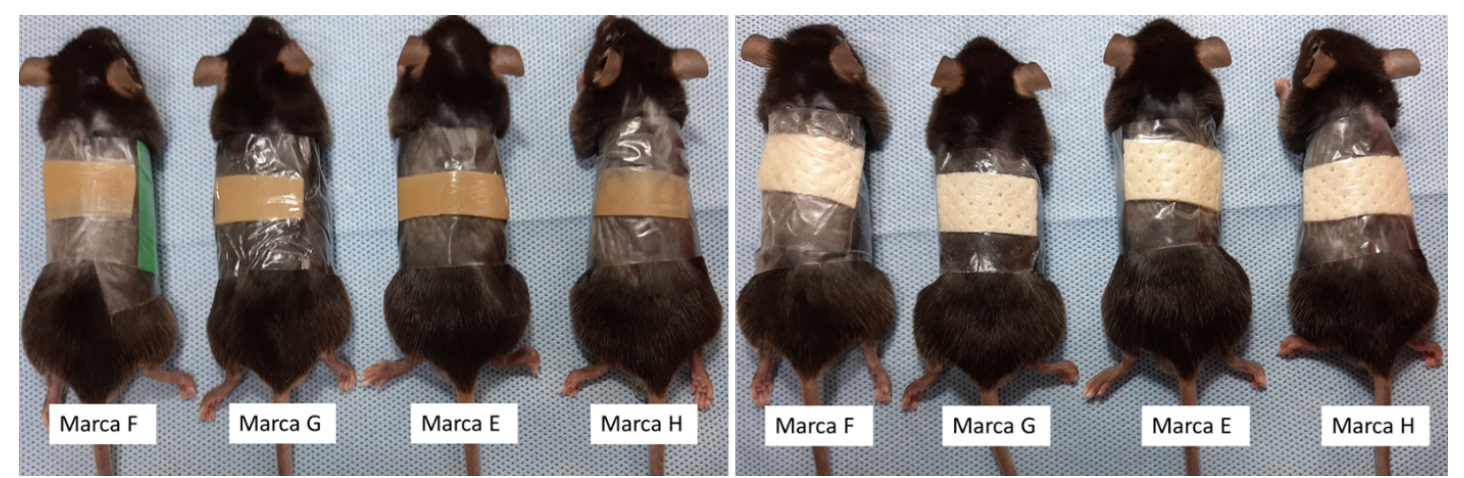

Figura 2. Técnicas de fixação utilizando o filme de poliuretano transparente como cobertura secundária. Belo Horizonte (MG) - 2019.
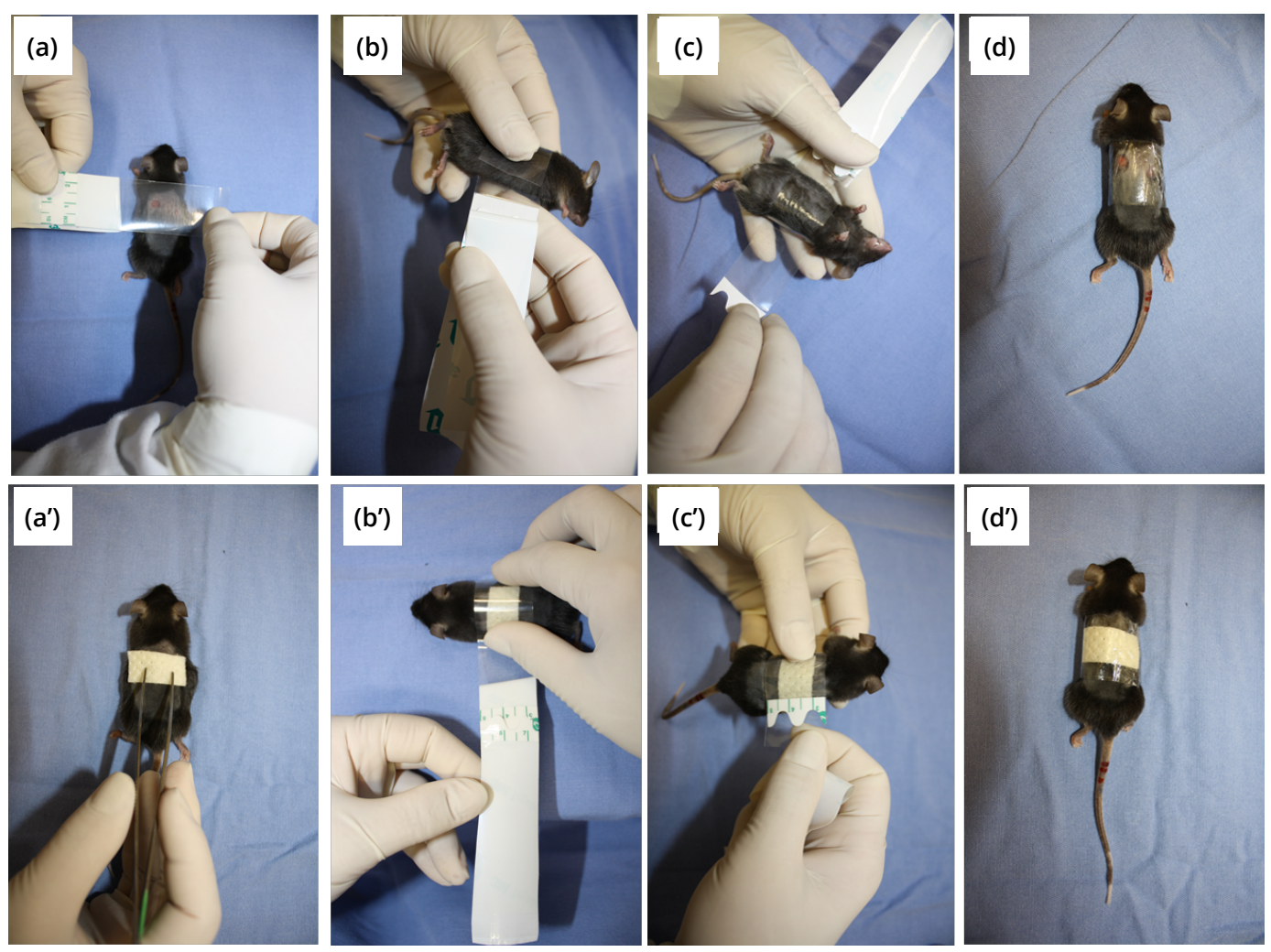

Figura 3. Sequência de aplicação do filme transparente como curativo primário (a a d) e como curativo secundário (a' a d'). Belo Horizonte (MG) - 2019. 


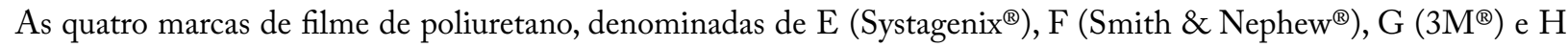
$\left(\right.$ Curatec $\left.^{\circledR}\right)$ foram aplicadas com uma volta completa ao redor do corpo do animal. Essa modalidade de fixação permitiu aos animais roerem o filme até seu rompimento, com exposição da cobertura e da ferida. O tempo de permanência do curativo foi de até 36 horas para o filme das marcas $\mathrm{E}$ e G, e inferior a 24 horas para as marcas $\mathrm{F}$ e $\mathrm{H}$.

As mesmas marcas de filme de poliuretano foram aplicadas dando duas voltas completas ao redor do corpo do animal. O tempo de permanência do curativo foi superior para as marcas $\mathrm{E}$ (Systagenix $\left.{ }^{\circledR}\right)$ e $\mathrm{G}\left(3 \mathrm{M}^{\circledR}\right.$ ), com 48 e 96 horas, respectivamente. As marcas F (Smith \& Nephew $\left.{ }^{\circledR}\right)$ e H $\left(\right.$ Curatec $\left.^{\circledR}\right)$ apresentaram tempo de 24 horas e inferior a 24 horas, respectivamente.

A avaliação da cobertura para aplicação sobre as feridas confirmou que o formato retangular na dimensão de $1 \mathrm{~cm}$ de comprimento por $2 \mathrm{~cm}$ de largura (vertical $\mathrm{x}$ horizontal) apresentou melhor performance para manutenção do curativo sobre $o$ leito da ferida. Neste experimento não foram observados eventos adversos na pele ao redor das feridas. Os curativos aplicados foram mantidos e observados até que o próprio animal os removessem ou que ocorresse perda da adesão (descolamento natural) do curativo. Esse posicionamento considerou que o objetivo deste estudo era avaliar o tempo de permanência do curativo sobre as feridas, então não foram realizadas intervenções, como remoção ou troca pontual do curativo.

Os resultados permitiram estabelecer recomendações para adoção do modelo de fixação do curativo (Tabela 2).

Tabela 2. Padronizações para confecção de ferida excisional, aplicação e fixação de curativos. Belo Horizonte (MG) - 2020.

\begin{tabular}{|c|c|}
\hline Variável padronizada & Resultados \\
\hline Local para confecção da ferida excisional & Região dorsal média* \\
\hline Tamanho da ferida (punch cirúrgico) & $5 \mathrm{~mm}^{*}$ \\
\hline Distância entre as feridas & 0,5 a 1,0 cm na direção vertical e horizontal ${ }^{* *}$ \\
\hline Número de feridas a serem confeccionadas & 2 ou mais conforme o estudo proposto** \\
\hline Formato e tamanho da cobertura oclusiva & Retangular com $1 \mathrm{~cm}$ de comprimento $\times 2 \mathrm{~cm}$ de largura (vertical $\times$ horizontal) ${ }^{* *}$ \\
\hline Produto padronizado para fixação curativo & Filme de poliuretano da marca $\mathrm{G}(3 \mathrm{M})^{* *}$ \\
\hline Formato do filme de poliuretano (fixação) & Retangular** \\
\hline Tamanho do filme de poliuretano (fixação) & $3 \mathrm{~cm}$ de comprimento $\times 15 \mathrm{~cm}$ de largura (vertical $\times$ horizontal) ${ }^{\star *}$ \\
\hline
\end{tabular}

*Adaptado de Canesso et al, 2014; ** Dados da pesquisa

\section{DISCUSSÃO}

O tratamento de feridas cutâneas, apesar do contínuo avanço na geração de evidências clínicas, ainda é desafio para profissionais de saúde, sendo de fundamental importância o desenvolvimento de pesquisas pré-clínicas a fim de encontrar novas tecnologias e, principalmente, notabilizar os produtos efetivos, que cumprem a proposta apresentada pela indústria.

As diferenças entre espécies de camundongos (Mus musculus) na reparação da pele murina e humana, como contração promovida pelo panículo carnoso (camada muscular) e papel de nichos específicos de células-tronco da pele, não impedem a realização de estudos pré-clínicos. O modelo murino, apesar das inúmeras diferenças morfofuncionais, imunológicas e genéticas, tem contribuído muito para compreensão do reparo cutâneo normal e patológico em humanos. A cura da ferida cutânea é semelhante em humanos e camundongos quando se consideram as fases distintas e sobrepostas de eventos celulares e moleculares altamente complexos: homeostase, inflamação, proliferação e remodelação ${ }^{11}$.

O camundongo foi escolhido para este estudo por ser o modelo animal mais comumente usado, especialmente em estudos de fisiologia e bioquímica, pois são fáceis de manusear e manter, além de economicamente acessíveis. Eles podem ser padronizados por idade, sexo, história e predisposição genética, e permite o uso de um número relativamente alto de animais para validação estatística ${ }^{11}$. No entanto, o camundongo tem corpo pequeno, o que dificulta fixação e manutençao dos curativos na avaliaçao de tratamento de feridas.

A região dorsal média foi definida como o melhor local para confecção das feridas excisionais nos camundongos da linhagem C57BL/6 devido à constituição física desses animais corresponder à maior área para a aplicação e adesão de 
curativos. Também se delimitou que seriam confeccionadas duas feridas no dorso desses animais para que a aplicação e fixação do curativo ocorressem de forma mais próxima à biofísica envolvida no tratamento de feridas. Além disso, definiu-se que a distância mínima entre as feridas seria de 0,5 a $1,0 \mathrm{~cm}$ em ambas as direções (vertical e horizontal), principalmente quando se tratar de estudos que envolvam confecção de número de feridas excisionais $\geq$ a 29 .

As avaliações demonstraram que a aplicação da cobertura em bloco único (retângulo de $1 \mathrm{~cm} \times 2 \mathrm{~cm}$ ) foi a técnica mais apropriada, pois permitiu a oclusão da área das feridas e assegurou pequena margem de pele exposta ao redor da ferida, diminuindo o tempo demandado para aplicação da cobertura e fixação do curativo, facilitando o manuseio da cobertura e, consequentemente, reduzindo manipulação e estresse do animal.

O modelo de feridas cutâneas excisionais usado como referência, que estabelece a confecção de quatro feridas no dorso do camundongo ${ }^{9}$, é reprodutível, além de amplamente aceito para o estudo de feridas cutâneas. Da mesma forma, a quantidade de feridas a ser confeccionada é diretamente proporcional à quantidade de material necessário para análises histológicas e/ou imuno-histoquímicas propostas.

Assim, a adaptação desse modelo para duas feridas contribui para manutenção do bem-estar dos animais durante o experimento, pois sua espoliação é reduzida em $50 \%$ e a possibilidade de desconforto e dor é menor que no modelo de quatro feridas cutâneas.

Ao término desse estudo, definiu-se que a melhor fixação do curativo é aquela realizada com filme de poliuretano transparente não estéril da marca $\mathrm{G}\left(3 \mathrm{M}^{\circledR}\right)$, medindo $3 \mathrm{~cm}$ de comprimento por $15 \mathrm{~cm}$ de largura, aplicado sobre a cobertura primária ou sobre os diferentes tipos de produtos para tratamento de feridas.

As dimensões do filme de poliuretano que permitiu a aplicação em duas voltas completas ao redor do corpo do camundongo garantiu maior tempo de permanência do curativo ( 96 horas) quando comparada com apenas uma volta, que permitiu um tempo de até 48 horas. Além disso, o comprimento garante que o filme de poliuretano seja aplicado no animal de forma a sobrepor a cobertura primária utilizada, garantindo uma margem de segurança para a aderência do produto na pele do animal.

Observa-se grande número de estudos desenvolvidos em modelos experimentais ${ }^{12,13}$. No entanto, esses modelos utilizados para avaliação do tratamento de feridas não contemplam, em sua totalidade, os princípios da cobertura ideal. Muitos não são capazes de proporcionar ambiente adequado para cicatrização e materializar a realidade da prática clínica.

Os produtos utilizados no estudo para fixação de curativos são rotineiramente adotados pelos profissionais da prática clínica. A escolha desses produtos teve relação direta com localização da ferida e características do produto utilizado para tratá-1a.

Alguns estudos experimentais em modelos murinos não citam ou não descrevem os métodos utilizados de forma clara para aplicação e fixação do curativo ${ }^{14,15}$. Os principais desafios para replicação desses estudos são lacunas na informação e variações na forma de aplicar os produtos investigados pelos pesquisadores.

Dentre os estudos experimentais publicados, alguns descreveram formas de fixação de curativo em modelos animais ${ }^{10,16,17}$ que serviram de apoio e orientação para padronização do modelo de curativos empregado neste estudo em questão.

Um estudo ${ }^{16}$ descreve o uso de membrana de biopolímero fixada com curativo convencional (gazes estéreis e esparadrapo) no tratamento de feridas cutâneas excisionais em ratos, sendo a troca realizada a cada 2 ou 3 dias, durante os tempos experimentais de 7,14, 21 e 40 dias após confecção das feridas. No entanto, esse modelo de fixação não funcionou nas avaliações realizadas neste estudo.

Uma pesquisa envolvendo feridas de pele de espessura total de $6 \mathrm{~mm}$, feitas no dorso dos camundongos, foram tratadas com nanopartículas de $\alpha$-gal (AGN). O produto foi aplicado topicamente nos dias 0 e 1 após o ferimento. A seguir, as feridas foram ocluídas com filme transparente Tegaderm ${ }^{\mathrm{TM}}\left(3 \mathrm{M}^{\circledR}\right)$ e os animais envolvidos circunferencialmente com atadura autoaderente Coban ${ }^{\mathrm{TM}}\left(3 \mathrm{M}^{\circledR}\right)$. A agregação da cobertura e atadura apresentou capacidade de manter as nanopartículas sobre a ferida ${ }^{17}$.

Em outro estudo ${ }^{18}$ a cobertura de silicone foi suturada com fios de nylon para avaliação de cicatrização de feridas cutâneas excisionais em animais com doença renal crônica induzida. Imediatamente após a aplicação dessa placa foi aplicado filme de poliuretano $(3 \mathrm{M})$ como cobertura secundária. $\mathrm{O}$ tecido das feridas foi coletado nos tempos de 3, 7 e 14 dias após 
sua confecção, ocasião em que foi realizada a remoção da fixação. Esse filme de poliuretano foi o mesmo do estudo que conseguiu manter o curativo no lugar por 96 horas, quando utilizado com duas voltas sobre o corpo do camundongo.

Outro estudo também empregou a sutura para manter a cobertura sobre a ferida ${ }^{10}$. Há descrição da fixação de um gel composto por plasma rico em plaquetas no tratamento tópico de queimaduras de segundo e terceiro graus induzidas cirurgicamente. O gel foi aplicado sobre a lesão e fixado por meio de um disco de plástico semirrígido preso ao redor da ferida com pontos cirúrgicos. Em seguida, o pesquisador envolveu o tórax dos animais com fita adesiva para evitar remoção do curativo por eles. A sutura do disco foi mantida por 5 dias e após esse período não foi aplicado curativo sobre as feridas.

Assim como ocorreu nos estudos citados, adotou-se, nesta pesquisa, a proposta da cobertura secundária por meio da utilização do filme de poliuretano. No entanto, excluiu-se a sutura para manter o curativo sobre a ferida, pois essa prática pode interferir no processo de cicatrização por ser fonte de trauma durante sua realização. Além disso, cada troca de curativo demanda confecção de nova sutura.

A fixação com filme de poliuretano foi testada, avaliada e ajustada para duas voltas sobre o dorso do animal, possibilitando padronização da fixação de curativos nos estudos realizados pelos pesquisadores para avaliação de tratamento das feridas em modelo animal (camundongo).

Para confeç̧ão das feridas foram mantidos os critérios sobre local e tamanho da ferida. Considerou-se que o punch cirúrgico de $5 \mathrm{~mm}$ é suficiente para confecção da ferida e remoção do tecido. Em relação ao local, constatou-se que quanto mais centralizada for a disposição da ferida (região dorsal média) maior a possibilidade de adesão e fixação do curativo. Tais fatos facilitam a aplicação da cobertura e a fixação do curativo no camundongo.

O filme de poliuretano pode ser utilizado como cobertura primária para promover oclusão da lesão ou como cobertura secundária, ou seja, para fixação do curativo aplicado. Os resultados alcançados durante o experimento de padronização de fixação de curativo têm similaridade com os procedimentos realizados pelos profissionais da prática clínica para fixação de curativos das feridas submetidas ao tratamento. As feridas crônicas guardam maior semelhança porque demandam troca frequente de curativos por longo período de tempo. Essa característica requer maior cuidado dos profissionais para implementação de cuidados que visem manutenção da integridade da pele ao redor da ferida, local em que os curativos são aderidos.

Apesar do progresso na pesquisa translacional sobre cicatrização de feridas de pele nas últimas décadas, nenhum modelo animal prevê totalmente todos os resultados clínicos ${ }^{11}$. Entretanto, o padrão para fixação do curativo é essencial para garantir que o tratamento escolhido permaneça sobre a ferida do dorso do camundongo no tempo estabelecido, além de preservar a integridade da pele ao redor da ferida.

O modelo experimental materializa, em parte, o processo de troca de curativos no tratamento de feridas realizada pelo enfermeiro a fim de auxiliar no desenvolvimento de novas pesquisas na área. Foi possível estabelecer modelo de fixação do curativo em camundongos com durabilidade de 96 horas com utilização do filme de poliuretano da marca $\mathrm{G}\left(3 \mathrm{M}^{\circledR}\right)$, cortado no tamanho $3 \mathrm{~cm}$ de comprimento por $15 \mathrm{~cm}$ de largura, dando duas voltas no corpo do animal. $O$ tempo de permanência do curativo atende à demanda dos seguimentos do experimento com animais. Dessa forma, esse modelo contribuirá com os enfermeiros na fixação de curativos na sua prática e ainda durante pesquisas que envolvam análise de coberturas, tratamento da ferida e reparação tecidual.

\section{CONCLUSÃO}

O estudo apresenta avanço no conhecimento, pois estabelece modelo de fixação de curativos para feridas em camundongos com produto disponível no Brasil e compatível com a estrutura copórea do animal. Além disso, o filme de poliutetano da marca $\mathrm{G}\left(3 \mathrm{M}^{\circledR}\right)$ e a técnica de envolver o corpo do camundongo com duas voltas foram resistentes aos movimentos e ação dos dentes do animal.

Recomenda-de que o modelo de fixação proposto seja utilizado pelos enfermeiros. Ele também deve ser expandido para outros animais para confirmação da efetividade do produto (filme de poliuretano) e técnica (duas voltas) com ajustes necessários na dimensão do filme (largura x comprimento), conforme o tamaho da ferida realizada e sua localização. 


\section{CONTRIBUIÇÃO DOS AUTORES}

Conceitualização: Borges EL e Amorim GL; Metodologia: Borges EL; Investigação: Amorim GL, Guillen MRS e Vieira PC; Redação - Primeira versão: Amorim GL e Guillen MRS; Redação - Revisão \& Edição: Borges EL; Aquisição de Financiamento: Borges EL e Amorim GL; Recursos: Amorim GL, Guillen MRS e Vieira PC; Supervisão: Borges EL.

\section{DISPONIBILIDADE DE DADOS DE PESQUISA}

Todos os dados foram gerados ou analisados no presente estudo

\section{FINANCIAMENTO}

Fundação de Amparo à Pesquisa do Estado de Minas Gerais

https://doi.org/10.13039/501100004901

Grant No: CDS-APQ-00904-15

\section{AGRADECIMENTOS}

Departamento de Fisiologia e Biofísica da Universidade Federal de Minas Gerais - Instituto de Ciências Biológicas pelo apoio logístico na utilização dos espaços e equipamentos.

\section{REFERÊNCIAS}

1. Storey S, Wagnes L, LaMothe J, Pittman J, Cohee A, Newhouse R. Building evidence-based nursing practice capacity in a large statewide health system: A Multimodal Approach. J Nurs Adm. 2019;49(4):208-14. https://doi.org/10.1097/ NNA.0000000000000739

2. Perry CJ, Lawrence AJ. Hurdles in basic science translation. Front Pharmacol. 2017;8:478. https://doi.org/10.3389/ fphar.2017.00478

3. Rowsey PJ. Using animals in nursing research: bridging gaps between bench, bedside, and practice. West J Nurs Res. 2015;37(12): 1515-6. https://doi.org/10.1177/0193945915578815

4. Lodhi S, Vadnere GP. Relevance and perspectives of experimental wound models in wound healing research. Asian J Pharm Clin Res. 2017;10(7):57-62. https://doi.org/10.22159/ajpcr.2017.v10i7.18276

5. Cai H, Li G. Efficacy of alginate-and chitosan-based scaffolds on the healing of diabetic skin wounds in animal experimental models and cell studies: a systematic review. Wound Rep Reg. 2020; 28(6):751-71. https://doi.org/10.1111/wrr.12857

6. Parnell LKS, Volk SW. The Evolution of Animal Models in Wound Healing Research: 1993-2017Adv in wound care (New Rochelle). 2019;8(12):692-702. https://doi.org/10.1089/wound.2019.1098

7. $\mathrm{Hu}$ J, Guo S, Hu H, Sun J. Systematic review of the efficacy of topical haemoglobin therapy for wound healing. Int Wound J. 2020;17:1323-30. https://doi.org/10.1111/iwj.13392

8. Cashion A, Pickler RH. What Will I Bring: Nurse Scientists' Contributions to Interdisciplinary Collaboration. Nurs Res. 2018;67(5):347-48. https://doi.org/10.1097/NNR.0000000000000299

9. Canesso MCC, Vieira AT, Castro TBR, Schirmer BGA, Cisalpino D, Martins FS et al. Skin wound healing is accelerated and scarless in the absence of commensal microbiota. J Immunol. 2014;193(10):5171-80. https://doi.org/10.4049/jimmunol.1400625

10. Masson-Meyers DS, Andrade TAM, Caetano GF, Guimaraes FR, Leite MN, Leite SN et al. Experimental models and methods for cutaneous wound healing assessment. Int J Exp Pathol. 2020;101(1-2):21-37. https://doi.org/10.1111/iep.12346

11. Zomer HD, Trentin AG. Skin wound healing in humans and mice: challenges in translational research. J Dermatol Sci. 2018; 90(1):3-12. https://doi.org/10.1016/j.jdermsci.2017.12.009 
12. Cetinkaya RA, Yilmaz S, Ünlü A, Petrone P, Marini C, Karabulut E et al. The efficacy of platelet-rich plasma gel in MRSA-related surgical wound infection treatment: an experimental study in an animal model. Eur J Trauma Emerg Surg. 2018;44(6):859-67. https://doi.org/10.1007/s00068-017-0852-0

13. Nikpasand A, Parvizi MR. Evaluation of the effect of titatnium dioxide nanoparticles/gelatin composite on infected skin wound healing; an animal model study. Bull Emerg Trauma. 2019;7(4):366-72. https://doi.org/10.29252/beat-070405

14. Park SA, Covert J, Teixeira L, Motta MJ, DeRemer SL, Abbott NL et al. Importance of defining experimental conditions in a mouse excisional wound model. Wound Repair Regen. 2015;23(2):251-61. https://doi.org/10.1111/wrr.12272

15. Stoffel JJ, Riedi PLK, Romdhane BH. A multimodel regime for evaluating effectiveness of antimicrobial wound care products in microbial biofilms. Wound Repair Regen. 2020;28(4):438-47. https://doi.org/10.1111/wrr.12806

16. Lucena MT, Melo Júnior MR, Lira MMM, Castro CMMB, Cavalcanti LA, Menezes MA et al. Biocompatibility and cutaneous reactivity of cellulosic polysaccharide film in induced skin wounds in rats. J Mater Sci Mater Med. 2015;26(2):82. https://doi. org/10.1007/s10856-015-5410-x

17. Kaymakcalan OE, Abadeer A, Goldufsky JW, Galili U, Karinja SJ, Dong X. et al. Topical a-Gal nanoparticles accelerate diabetic wound healing. Exp Dermatol. 2020;29(4):404-13. https://doi.org/10.1111/exd.14084

18. Seth AK, De la Garza M, Fang RC, Hong SJ, Galiano RD. Excisional wound healing is delayed in a murine model of chronic kidney disease. Plos One. 2013;8(3):e59979. https://doi.org/10.1371/journal.pone.0059979 